Public Abstract

First Name:Michael

Middle Name:Charles

Last Name:Stambaugh

Adviser's First Name:Richard

Adviser's Last Name:Guyette

Co-Adviser's First Name:

Co-Adviser's Last Name:

Graduation Term:FS 2008

Department:Forestry

Degree:PhD

\title{
Title:FIRE RISK ASSESSMENT OF THE WESTERN PORTION OF THE CENTRAL HARDWOODS FOREST REGION
}

This study examined how fire risk, a combination of fuels conditions and fire probabilities, varied across a large portion of Missouri, Illinois, and Indiana. Case studies were conducted to evaluate the fuel loading variability in Missouri Ozark forests, determine the temporal variability in fuel accumulation rates, and quantify the role of topographic roughness in fire regimes. Using knowledge gained from these case studies, two regional scale studies were conducted describing 1) variability in fuel loading and hazard and, 2) fire probabilities. Overall, litter hazard appeared to be relatively homogeneous throughout the study area with greatest levels attained in southeastern Missouri. Month of year and drought condition are likely the most important parameters concerning fuel hazard. For the fire probability study, a large set of fire occurrence records ( $>12,000$ ) for the period 1986 to 2008 were used to develop a predictive model of fire probability. The fire probability model showed fire probabilities to be substantially greater in the southern Ozark Highlands compared to the northern Ozarks and most of Illinois and Indiana. Areas of highest fire risk were identified as being primarily located on Mark Twain National Forest lands. The model appears to have captured much of the variability observed in the modern fire locations, however likely did not characterize the variability associated with known cultural patterns related to fires. 